ЛИа НАППА, И. КЛЕСМЕНТ, Н. ВИНК, К. КАИЛАС

\title{
ДЕСТРУКТИВНАЯ ГИДРОГЕНИЗАЦИЯ ДИКТИОНЕМОВЫХ СЛАНЦЕВ
}

Диктионемовый сланец характеризуется относительно низким содержанием органического вещества (ОВ) - в среднем 15\%. Минеральная часть диктионемового сланца состоит в основном из $\mathrm{SiO}_{2}(50 \%)$ и $\mathrm{Al}_{2} \mathrm{O}_{3}$ $(\approx 13 \%)$, высоко и содержание пиритной серы $(2,4 \%)$ [']. Полукоксование диктионемового сланца дает низкие выходы смолы, при этом на выход смолы влияет, кроме состава ОВ, и минеральная часть. Так, с уменьшением содержания ОВ снижается и выход смолы [2]. При деструкции бедных сланцев самой трудной задачей является разрушение связи между органическим и минеральным веществом.

В настоящем исследовании представлены результаты изучения деструктивной гидрогенизации диктионемового сланца с целью более полного превращения его в легкоанализируемые продукты. Процессы передачи водорода проходят более активно в жидкой фазе, присутствие воды или растворителя улучшает также и теплопередачу. Вода одновременно действует и как гидрирующий реагент. Опыты [3] показали, что кукерсит конвертируется в жидкие и газообразные продукты водой при $400-430^{\circ} \mathrm{C}$ в течение 30 мин на $93 \%$.

- Исходным сырьем служил диктионемовый сланец из месторождений Маарду (западная фация) и Тоолсе (восточная фация); их характеристику см. в табл. 1 .

Выход битумоида колеблется от 0,6 до $1,5 \%$ на ОВ в зависимости от месторождения [5]. Полукоксование и гидрогенизацию сланца, разделение полученных продуктов, а также их анализ осуществляли по методике [6].

таблица 1

Характеристика проб диктионемового сланца *

\begin{tabular}{|c|c|c|c|c|c|c|c|}
\hline \multirow{2}{*}{ Месторождение } & \multirow{2}{*}{$A^{\circ}$} & \multirow{2}{*}{$\begin{array}{c}\mathrm{CO}_{2}^{\mathrm{c}} \\
\text { (минер.) }\end{array}$} & \multicolumn{5}{|c|}{ Элементный состав, \% } \\
\hline & & & $\mathrm{C}$ & $\mathrm{H}$ & $\mathrm{N}$ & $\mathrm{S}$ & 0 \\
\hline $\begin{array}{l}\text { Маарду } \\
\text { Тоолсе }\end{array}$ & $\begin{array}{l}79,2 \\
80,5\end{array}$ & $\begin{array}{l}0,2 \\
0,1\end{array}$ & $\begin{array}{l}70,5 \\
69,0\end{array}$ & $\begin{array}{l}8,3 \\
7,6\end{array}$ & $\begin{array}{l}2,5 \\
2,1\end{array}$ & $\begin{array}{l}4,2 \\
3,2\end{array}$ & $\begin{array}{l}14,5 \\
17,8\end{array}$ \\
\hline
\end{tabular}

* ОВ сланца рассчитан наснове [4] графически. 
Таблица 2

Выход и характеристика продуктов деструкции диктионемового сланца месторождения Тоолсе $\left(370^{\circ} \mathrm{C}, 4\right.$ ч)

\begin{tabular}{|c|c|c|c|c|c|c|}
\hline & \multirow[b]{2}{*}{ Показатели } & \multicolumn{2}{|c|}{ Гидрогенизация } & \multicolumn{2}{|c|}{ Конверсия } & \multirow[b]{2}{*}{$\begin{array}{l}\text { Полу- } \\
\text { коксо- } \\
\text { вание }\end{array}$} \\
\hline & & $\begin{array}{l}\text { В среде } \\
\text { цикло- } \\
\text { гексана }\end{array}$ & $\left|\begin{array}{c}\text { В среде } \\
\text { водного } \\
\text { раствора } \\
\text { формиата }\end{array}\right|$ & Водой & $\begin{array}{c}5 \% \text {-ным } \\
\text { раство- } \\
\text { ром } \\
\mathrm{NaOH}\end{array}$ & \\
\hline
\end{tabular}

Рабочее давление, $М П а$

Выход, вес. \% от керогена:

смола твердый остаток вода, газ и потери

Характеристика смолы: плотность

показатель преломления

Элементный состав смолы, вес. \% углерод

водород

азот

кислород

Групповой состав, вес. $\%$

парафины

олефины

алкилбензолы

полициклическая ароматика

гетеросоединения

фенолы

$\begin{array}{ccccc}15,0 & 27,5 & 30,0 & 26,0 & - \\ 40,0 & 10,1 & 7,1 & 47,4 & 9,1 \\ 36,4 & 56,0 & 58,0 & 21,0 & 58,9 \\ 23,6 & 33,9 & 34,9 & 31,1 & 32,0 \\ 0,992 & 1,030 & 1,016 & 1,044 & 0,990 \\ 1,572 & 1,579 & 1,547 & 1,591 & 1,557 \\ 86,8 & 82,5 & 82,2 & 82,8 & 83,7 \\ 8,9 & 8,6 & 9,1 & 8,6 & 9,0 \\ 1,5 & 1,0 & 0,8 & 1,7 & 1,2 \\ 2,8 & 7,9 & 7,9 & 6,9 & 6,1 \\ 16 & 10 & 8 & 13 & 6 \\ -18 & -12 & -16 & -11 & 4 \\ 27 & 30 & 27 & 27 & 9 \\ 39 & 48 & 49 & 49 & 44 \\ 1,3 & \text { не опр. } & \text { не опр. } & 1,8 & \text { не опр. }\end{array}$

Таблица 3

Выход и характеристика продуктов деструкции диктионемового сланца месторождения Маарду $\left(370^{\circ} \mathrm{C}, 4\right.$ ч)

\begin{tabular}{c|c|c|c|c}
\hline Показатели & $\begin{array}{c}\text { Гидрогени- } \\
\text { зация в } \\
\text { водном } \\
\text { растворе } \\
\text { формиата }\end{array}$ & Водой & $\begin{array}{c}5 \% \text {-ным вод- } \\
\text { ным раство- } \\
\text { ром NaOH }\end{array}$ & $\begin{array}{c}\text { Полукок- } \\
\text { сование }\end{array}$ \\
\hline
\end{tabular}

Рабочее давление, $M \Pi а$

Выход, вес. \% от керогена смола

твердый остаток

вода, газ и потери

Характеристика смолы:

плотность

показатель преломления

Элементный состав, вес. \%:

углерод
водород
азот

кислород

Групповой состав смолы, вес. \% парафины

олефины

алкилбензолы

полициклическая ароматика

гетеросоединения

фенолы

$\begin{array}{rrrr}27,0 & 27,0 & 26,0 & - \\ 18,2 & 12,8 & 49,1 & 13,5 \\ 52,3 & 52,7 & 15,8 & 62,5 \\ 34,5 & 29,5 & 35,1 & 24,3 \\ & & & \\ 0,989 & 0,986 & 1,019 & 0,983 \\ 1,551 & 1,541 & 1,577 & 1,549 \\ & & & \\ 82,8 & 85,7 & 86.3 & 83,3 \\ 9,3 & 9,6 & 9,1 & 9,3 \\ 1,0 & 1,0 & 2,0 & 1,0 \\ 3,7 & 6,9 & 2,6 & 6,4\end{array}$

$\begin{array}{cccc}8 & 14 & 10 & 5 \\ 80 & -10 & 10 & 3 \\ 39 & 30 & 23 & 7 \\ 45 & 46 & 57 & 39 \\ \text { не опр. } & \text { не опр. } & 3,0 & 46\end{array}$


В автоклаве были проведены:

1. Конверсия водой, соотношение сланец : вода $1: 2$.

2. Конверсия 5\%-ным раствором щелочи; соотношение сланец: раствор щелочи $1: 1$; первоначальное давление водорода 20 ат.

3. Гидрогенизация за счет водорода, освобождающегося в результате реакции между формиатом натрия и воды; соотношение сланец: вода: : формиат $2: 2: 1$.

4. Каталитическая гидрогенизация в присутствии циклогексана; соотношение сланец:циклогексан $1: 2$; первоначальное давление водорода $20 a T$; катализатор $1 \%$ молибдата аммония на ОВ.

Во всех опытах, проведенных в одинаковых условиях, выходы продуктов гидрогенизации и полукоксования из диктионемового сланца месторождения Маарду были выше, чем из месторождения Тоолсе (см. табл. 2,3 ). Этот факт совпадает с ранними высказываниями геологов о различии керогенов диктионемовых сланцев из двух разных по геологическому возрасту фаций [7], а также с выводами о снижении выхода смолы с уменьшением содержания ОВ [2].

Из материального баланса вытекает, что самые низкие выходы смолы из обоих месторождений наблюдаются при конверсии водой и полукоксовании. При гидрогенизации в среде формиата выход смолы увеличивается на $15-30 \%$ по сравнению с полукоксованием. Особо резкое повышение выхода смолы имеет место при конверсии водой в присутствии $5 \%$-ного раствора щелочи, когда $\approx 50 \%$ ОВ превращается в смолу. Такого резкого увеличения выхода смолы у других сланцев не наблюдалось. По всей вероятности, это зависит, кроме различий в структуре самого керогена, также от различия в составе минерального вещества, очевидно, щелочь разрушает связи между органической и минеральной частями.

Образующиеся гидрогенизаты имеют близкий групповой состав, близки также их показатели преломления и удельные веса. Групповой состав показывает, что основная часть смолы, около $50 \%$, состоит из гетероатомных соединений, в том числе из кислородсодержащих, около $30 \%$ падает на полициклические ароматические соединения, алкилбензолы составляют в среднем $10-15 \%$, на долю алифатических углеводородов приходится $10-15 \%$. Фенолы были определены в трех пробах, их содержание в среднем $1,3-3,0 \%$.

По хроматограммам суммарных смол полукоксования (рис. 1) и гидрогенизации в среде циклогексана (рис. 2) ясно виден их ароматический характер, основные пики на хроматограммах соответствуют аякилбензолам, кипящим до $200^{\circ}$, и полициклическим ароматическим соединениям с более высокой температурой кипения.

Ранее нроведенные работы по изучению индивидуального состава углеводородной части смолы полукоксования [8,9], а также работы по окислительной деструкцин керогена щелочным перманганатом [10] и азотной кислотой [11] указывают на определенную роль ароматических структурных элементов в керогене диктионемового сланца.

Фракции неароматических соединений смолы полукоксования и смолы конверсии в $5 \%$-ном растворе щелочи приведены на рис. 3 . Фракция алифатических углеводородов смолы полукоксования состоит из нормальных и разветвленных парафинов от $\mathrm{C}_{9}$ до $\mathrm{C}_{23}$, нормальные олефины составляют около $50 \%$ от суммы парафинов. Наивысшую концентращню имеют более низкокипящие парафины $\mathrm{C}_{10}-\mathrm{C}_{13}$. Присутствуют и изопренондные структуры от $i \mathrm{C}_{16}$ до $i \mathrm{C}_{20}$. Фракция алифатиче- 


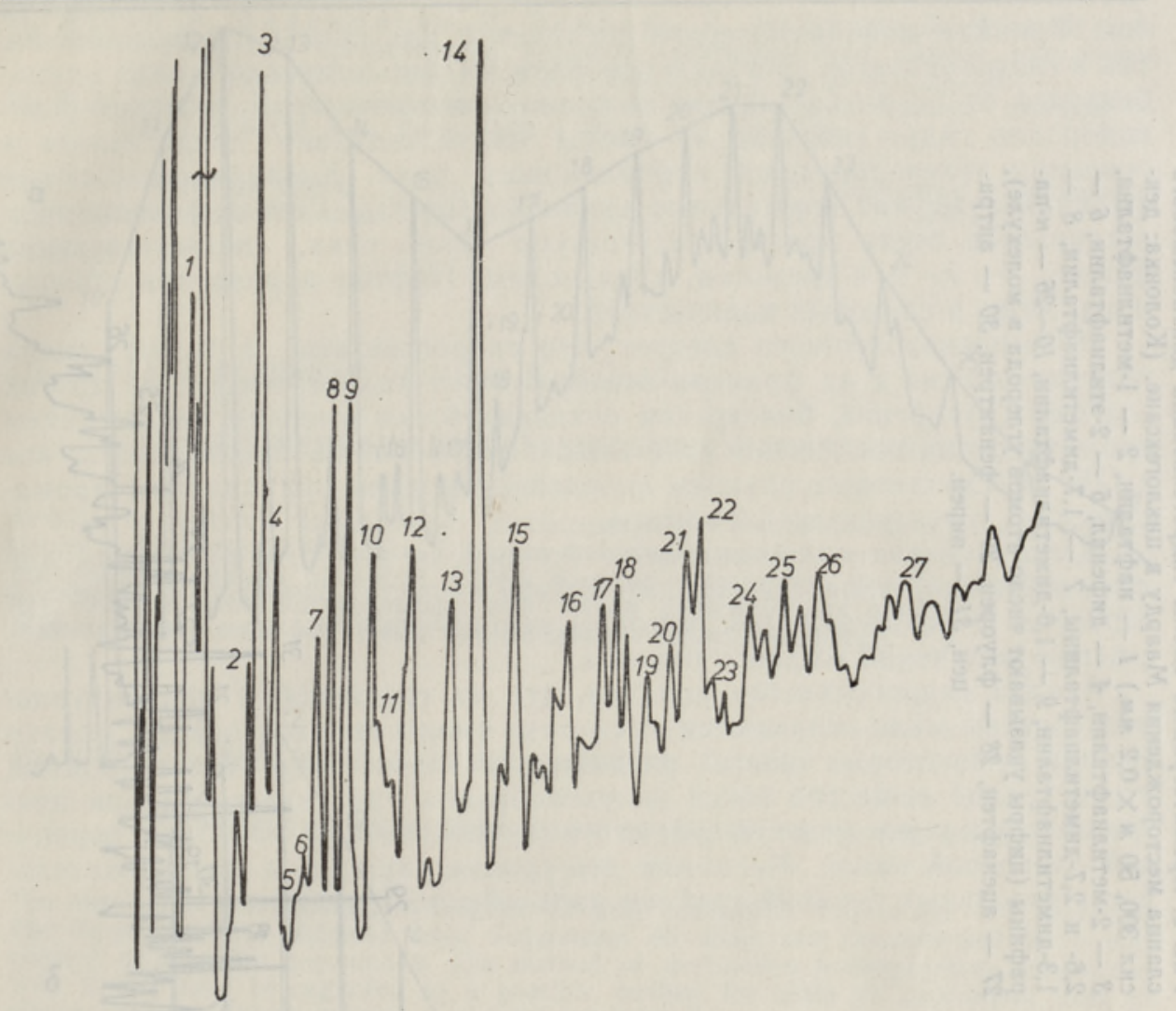

Рис. 1. Хроматограмма смолы полукоксования диктионемового сланца месторождения Маарду. (Колонка: $8 \%$ апьезона $L$ на хроматоне $N$-AW HMDS; $3,6 м \times 3$ мм.) 1 - метилбензол, 2 - этилбензол, 3 - 1,3- и 1,4-диметилбензолы, 4 - 1,2-диметилбензол, 5 - изопропилбензол, $6-$-п-пропилбензол, $7-1$-метил-3-этил- и 1-метил-4-этилбензолы, 8 - 1-метил-2-этил- и 1,3,5-триметилбензолы, $9-1,2,4$ триметилбензол, $10-1,2,3$-триметилбензол, $11-$ инден и 4-замещенный бензол, 12 - диметилбензолы, 13 - 1,2,4,5- и 1,2,3,5-тетраметилбензолы, 14 - метилинден, 15 - нафталин, 16 - метилтетралин, $17-2$-метилнафталин, $18-1$-метилнафталин, $19-$ дифенил, 20 - этилнафталин, 21 - 2,6- и 2,7-диметилнафталины, $22-1,7-$, 1,6- и 1,3-метилнафталины, $23-1,2$-диметилнафталин, 24 - аценафтен, 25 - триметилнафталин, 26 - флуорен.

ских углеводородов смолы конверсии состоит из нормальных и разветвленных парафинов от $\mathrm{C}_{9}$ до $\mathrm{C}_{28}$, основная часть падает на $\mathrm{C}_{10}-\mathrm{C}_{15}$. Обнаружены и изопреноидные структуры от $i \mathrm{C}_{16}$ до $i \mathrm{C}_{20}$, притом пристана $\left(i \mathrm{C}_{19}\right)$ и фитана $\left(i \mathrm{C}_{20}\right)$ меньше, чем во фракции смолы полукоксования. Хотя диктионемовый сланец значительно отличается от кукерсита по химическому составу и его залегание в геологическом разрезе ниже слоев кукерсита, все же состав алифатических углеводородов как смолы полукоксования, так и гидрогенизатов диктионемового сланца близок смоле кукерсита [12]. Из этого следует, что их исходным биологическим веществом могли быть одни и те же водоросли. Предполагается, что низшие водные организмы синтезировали алкановые цепи до $\mathrm{C}_{17}$, а углеводороды C>17 битумоида диктионемового сланца являются продуктами метаболизма сульфатвосстанавливающих бактерий $\left[{ }^{12}\right]$. Видимо, это относится и к длинноцепочечным углеводородам гидрогениза, 

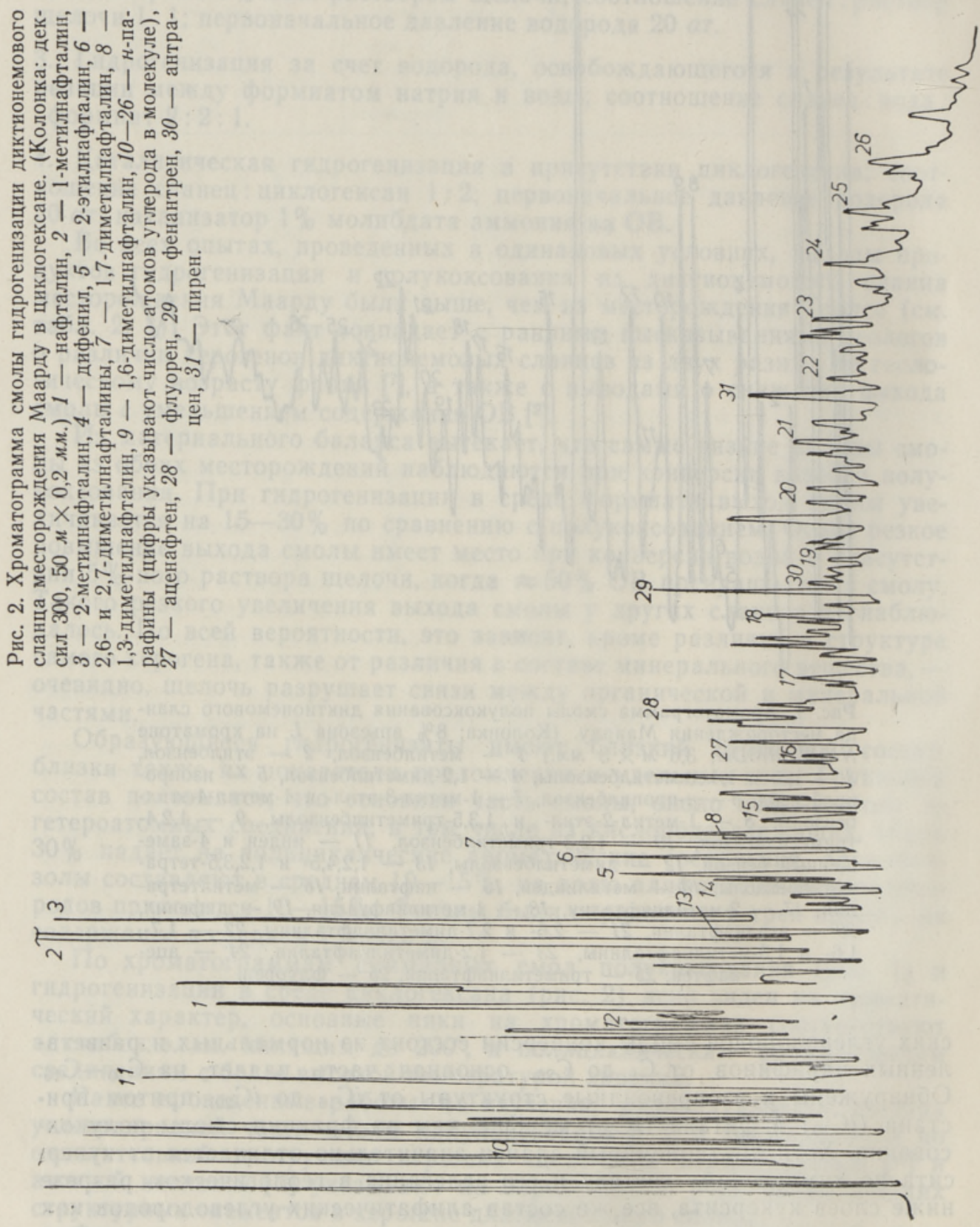


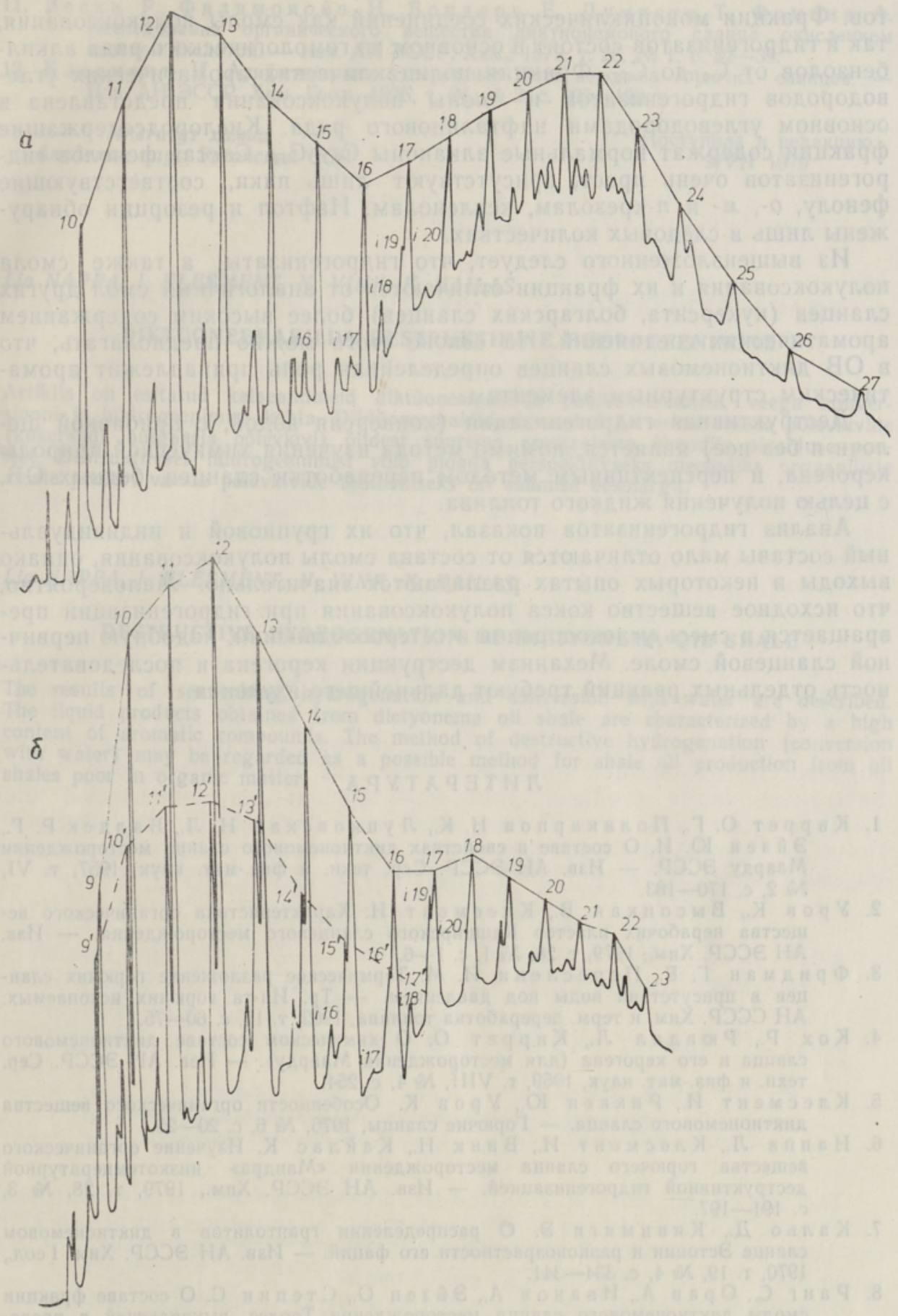

Рис. 3. Хроматограмма фракции алифатических углеводородов диктионемового сланца месторождения Маарду: a - гидрогенизата, полученного в среде $5 \%$-ного раствора щелочи, б- смолы полукоксования. (Колонка: $8 \%$ апьезона $L$ на хроматоне $N-A W$ $H M D S ; 3,6 \mu \times 3 м \mu$.) Цифры от 9 до 27 указывают число атомов углерода в молекуле $\mu$-парафинов и от $9^{\prime}$ до $17^{\prime}$-олефениов; $i \mathrm{C}_{16}-i \mathrm{C}_{20}-$ изопреноидные структуры. 
тов. Фракции моноциклических соединений как смолы полукоксования, так и гидрогенизатов состоят в основном из гомологического ряда алкилбензолов от $\mathrm{C}_{4}$ до $\mathrm{C}_{12}$. Фракция полициклических ароматических углеводородов гидрогенизатов и смолы полукоксования представлена в основном углеводородами нафталинового ряда. Кислородсодержащие фракции содержат нормальные алканоны $\mathrm{C}_{9}-\mathrm{C}_{19}$. Состав фенолов гидрогенизатов очень прост, присутствуют лишь пики, соответствующие фенолу, o-, $\boldsymbol{\text { - и }}$ n-крезолам, ксиленолам. Нафтол и резорцин обнаружены лишь в следовых количествах.

Из вышеизложенного следует, что гидрогенизаты, а также смола полукоксования и их фракции отличаются от аналогичных смол других сланцев (кукерсита, болгарских сланцев) более высоким содержанием ароматических соединений. На основе этого можно предполагать, что в ОВ диктионемовых сланцев определенная роль принадлежит ароматическим структурным элементам.

Деструктивная гидрогенизация (конверсия водой, с прибавкой щелочи и без нее) является, помимо метода изучения химической природы керогена, и перспективным методом переработки сланцев, бедных ОВ, с целью получения жидкого топлива.

Анализ гидрогенизатов показал, что их групповой и индивидуальный составы мало отличаются от состава смолы полукоксования, однако выходы в некоторых опытах различаются значительно. Маловероятно, что исходное вещество кокса полукоксования при гидрогенизации превращается в смесь углеводородов и гетеросоединений, подобную первичной сланцевой смоле. Механизм деструкции керогена и последовательность отдельных реакций требуют дальнейшего изучения.

\section{Л ИТЕ РАТ У Р А}

1. Киррет О.Г., Поликарпов Н. К., Луцковская Н. Л., Валдек Р. Г., Эй з ен Ю. И. О составе и свойствах диктионемового сланца месторождения Маарду ЭССР. - Изв. АН ЭССР. Сер. техн, и физ.-мат. наук, 1957, т. VI, № 2 , c. $170-183$.

2. Уров К., В ысоцкая В., Клесмент И. Характеристика органического вещества нерабочих пластов Кашпирского сланцевого месторождения. - Изв. АН ЭССР. Хим., 1979, т. 28, № 1, с. $1-6$.

3. Фридм ан Г. Е., Пе реслени И. М. Термическое разложение горючих сланцев в присутствии воды под давлением. - Тр. Ин-та горючнх ископаемых. АН СССР. Хим. и терм. переработка топлива, 1962 , т. 17 , с. $60-75$.

4. Кох Р., Рюндал Л., Кир рет О. О химическом составе диктионемового сланца и его керогена (для месторождения Маарду). - Изв. АН ЭССР. Сер. техн. и физ.-мат. наук, 1959, т. VIII, № 4, с. 254.

5. Клесмент И., Риккен Ю., У ров К. Особенности органического вещества диктионемового сланца. - Горючие сланцы, 1976, № 6, с. 20-25.

6. Н аппа Л., Клесмен т И., Винк Н., К айл а с К. Изучение органического вещества горючего сланца месторождения «Мандра» низкотемпературной деструктивной гидрогенизацией. - Изв. АН ЭССР. Хим., 1979, т. 28, № 3, c. $191-197$.

7. Кальо Д., Ки вимяги $Э$. О распределении граптолитов в диктионемовом сланце Эстонии и разновозрастности его фаций. - Изв. АН ЭССР. Хим. Геол., 1970 , т. 19, № 4, c. $334-341$.

8. Р анг С., О рав А., Ив анов А., Эйзен О., С тепин С. О составе фракции смолы диктионемового сланца месторождения Тоолсе, выкипающей в пределах $120-190^{\circ} \mathrm{C}$ - Изв. АН ЭССР. Хим. Геол., 1974, т. 23 , № 1, с. $27-30$.

9. $\mathrm{P}$ ан г С., О р а в А., Э й з ен О. О составе фракции смолы диктионемового сланца месторождения Тоолсе, выкипающей в пределах $190-270^{\circ} \mathrm{C}$. - Изв. АН ЭССР. Хим. Геол., 1975 , т. 24 , № 1, с. 10-13.

10. Е р усен ко В., Фомин а А. K вопросу об окислительной деструкции керогена диктионемового сланца щелочным перманганатом калия. Сообщ. второе. Изв. АН ЭССР. Сер. физ.-мат. и техн. наук, 1964, т. XIII, № 4, с. 319-329. 
11. Вески Р., Филимонова Н., Бондарь Е., Лумисте Т., Фомина А. Исследование органического вещества диктионемового сланца окислением азотной кислотой. - Изв. АН ӘССР. Хим., 1979, т. 28 , № 1, с. $32-39$.

12. Клесмен т И. Алифатические углеродные цепи керогена горючих сланцев. Изв. АН ЭССР. Хим. Геол., 1975, т. 24, № 2, с. 123-129.
Институт химии
Академии наук Эстонской ССР
Поступила в редакцию
9/VII 1979

Lia NAPPA, I. KLESMENT, N. VINK, K. KAILAS

\section{DIKTUONEEMAKILDA DESTRUKTIIVNE HUDROGEENIMINE}

Artiklis on esitatud katseandmeid diktüoneemakilda poolkoksistamise, veega konversiooni ja hüdrogeenimise kohta. Diktüoneemakildast saadud õli erineb teiste põlevkivide (kukersiidi, bulgaaria põlevkivi) õlidest suurema aromaatsete ühendite sisalduse poolest. Destruktiivset hüdrogeenimist võib pidada perspektiivseks meetodiks orgaaniliste ainete poolest vaeste põlevkivide töötlemiseks õli saamise eesmärgil.

Lia NAPPA, I. KLESMENT, N. VINK, K. KAILAS

\section{DESTRUCTIVE HYDROGENATION OF DICTYONEMA OIL SHALE}

The results of semicoking, hydrogenation and conversion with water are described. The liquid products obtained from dictyonema oil shale are characterized by a high content of aromatic compounds. The method of destructive hydrogenation (conversion with water) may be regarded as a possible method for shale oil production from oil shales poor in organic matter. 